\title{
ASO Visual Abstract: Invasive Lobular Breast Cancer-Data to Support Surgical Decision-Making
}

\section{Daniela Cocco, MD ${ }^{1}$, Ayat EISherif, $\mathrm{MD}^{1}$, Matthew D. Wright, $\mathrm{MD}^{2}$, Marcus S. Dempster, $\mathbf{M D}^{2}$,} Megan L. Kruse, $\mathrm{MD}^{2}$, Hong $\mathrm{Li}, \mathrm{MS}^{3}$, and Stephanie A. Valente, DO ${ }^{1}$

${ }^{1}$ Division of Breast Surgery, Department of General Surgery Cleveland Clinic, Cleveland Clinic, Cleveland, OH; ${ }^{2}$ Division of Breast Medical Oncology, Taussig Cancer Institute, Cleveland Clinic, Cleveland, $\mathrm{OH} ;{ }^{3}$ Department of Quantitative Health Science, Cleveland Clinic, Cleveland, $\mathrm{OH}$

Invasive lobular cancer is characterized by a challenging accurate clinical diagnosis due to its unique histopathology, high incidence of lymph node involvement, and early metastasis. Magnetic resonance imaging (MRI) improves identification of extent of disease; however, it does not improve clinical tumor or nodal staging concordance (https://doi.org/10.1245/s10434-021-10455-7).

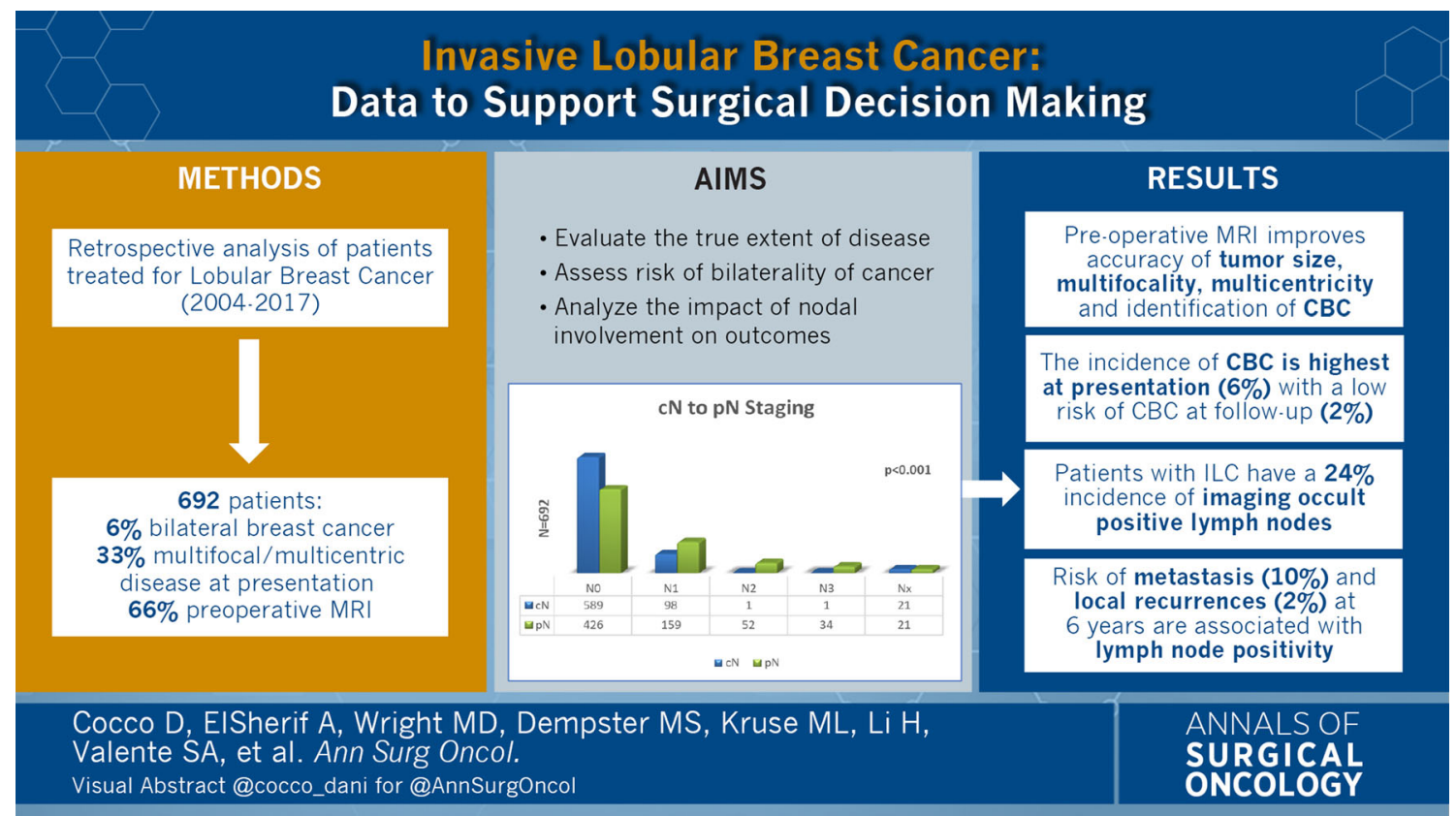

(C) Society of Surgical Oncology 2021

Published Online: 10 August 2021

S. A. Valente, DO

e-mail: Valents3@ccf.org

Publisher's Note Springer Nature remains neutral with regard to jurisdictional claims in published maps and institutional affiliations. 